infected tissue, we avoided having to administer lifelong antibiotics to the patient.

\section{References}

1. Hsu RB, Lin FY. Surgery for infected aneurysm of the aortic arch. $J$ Thorac Cardiovasc Surg. 2007;134:1157-62.
2. Fillmore AJ, Valentine RJ. Surgical mortality in patients with infected aortic aneurysms. J Am Coll Surg. 2003;196:435-41.

3. Aizawa K, Ohki S, Konishi H, Misawa Y. Extraanatomical ascending-abdominal aorta bypass with stump closure for aortic graft infection. Interact Cardiovasc Thorac Surg. 2008;7:646-7.

\title{
A simple method for the quantification and correction of aortic cusp prolapse by means of free margin plication
}

\author{
Munir Boodhwani, MD, MMSc, Laurent de Kerchove, MD, David Glineur, MD, and \\ Gebrine El Khoury, MD, Brussels, Belgium
}

Cusp prolapse is a common contributor to aortic insufficiency, occurring in $35 \%$ of patients undergoing aortic valve repair or valve-sparing surgery, ${ }^{1}$ and can be corrected by using a variety of surgical techniques, including free margin plication, triangular resection, and free margin resuspension. ${ }^{2-4}$ Although techniques for cusp prolapse assessment have been proposed, ${ }^{5}$ quantification of the degree of cusp prolapse can often be challenging, with the risk of undercorrection leaving residual prolapse or overcorrection leading to cusp restriction. We describe a simple method for the simultaneous quantification and correction of excess cusp tissue by means of free margin plication in the setting of a trileaflet aortic valve cusp prolapse.

\section{OPERATIVE TECHNIQUE}

A transverse aortotomy is performed $1 \mathrm{~cm}$ above the sinotubular junction, traction sutures are placed at the 3 commissures, and the distal aorta is retracted cephalad.

\section{Valve Assessment}

First, axial traction (perpendicular to the annular plane) is applied on the commissural sutures, which demonstrates the physiologic aortic valve closure position, and the area and height of coaptation can be observed. A prolapsing cusp will typically exhibit a transverse fibrous band at this time (Figure 1, A). Next, radial traction (parallel to the annular plane) is applied to the 3 commissural sutures, and the center of the cusp free margin can then be gently pushed down to-

\footnotetext{
From the Department of Cardiovascular and Thoracic Surgery Cliniques Universitaires Saint-Luc, Brussels, Belgium.

Disclosures: None.

Received for publication Feb 19, 2009; revisions received April 8, 2009; accepted for publication April 29, 2009; available ahead of print June 29, 2009.

Address for reprints: Munir Boodhwani, MD, MMSc, Service de Chirurgie Cardiovasculaire et Thoracique, Cliniques Universitaires Saint-Luc UCL 90, Avenue Hippocrate 10, Brussels B-1200, Belgium (E-mail: mboodhwani@ottawaheart.ca).

J Thorac Cardiovasc Surg 2010;139:1075-7

$0022-5223 / \$ 36.00$

Copyright (c) 2010 by The American Association for Thoracic Surgery

doi:10.1016/j.jtcvs.2009.04.037
}

ward the left ventricle with a forceps. A nonprolapsing cusp will remain at its physiologic coaptation level (halfway between the base of the cusp and its maximal height at the commissure), whereas a prolapsing cusp will be able to be pushed lower because of excessive cusp tissue.

\section{Free Margin Plication: Quantification and Repair}

A 7-0 polypropylene suture is passed through the center of the 2 nonprolapsing reference cusps, and gentle axial traction is applied (Figure 1, B). The prolapsing cusp is gently pulled parallel to the reference cusp, and a 6-0 polypropylene suture is passed through the prolapsing cusp from the aortic to ventricular side at the point at which it meets the center of the reference cusp (Figure 2, $A$ ). Next, the direction of traction on the prolapsing cusp is reversed, and the same suture is passed from the ventricular to the aortic side of the cusp, where it meets the middle of the reference cusp (Figure 2, $B$ ). The length of cusp free margin between the 2 ends of this 60 suture represents the quantity of excess free margin, which is then plicated by tying this suture with the excess tissue on the aortic side (Figure 2, $C$ ).

The plication is extended by about 5 to $10 \mathrm{~mm}$ onto the body of the aortic cusp by adding interrupted or running locked 6-0 polypropylene sutures (Figure 2, D). If there is significant excessive tissue, it can be shaved off with a scalpel or scissors, keeping sufficient tissue to bring the edges together.

\section{Technical Adjuncts}

When 2 cusps are prolapsing, a 7-0 suture is passed through the center of the third reference cusp. An adjacent prolapsing cusp is then pulled parallel to the reference cusp, and the 6-0 suture is passed through the free margin at the point at which it meets the center of the reference cusp. Next, taking advantage of symmetry, the suture is passed back through the cusp an equivalent distance from the cusp center on the other side. This then represents the amount of excess cusp tissue and is plicated as described above. This procedure is repeated for the other prolapsing 

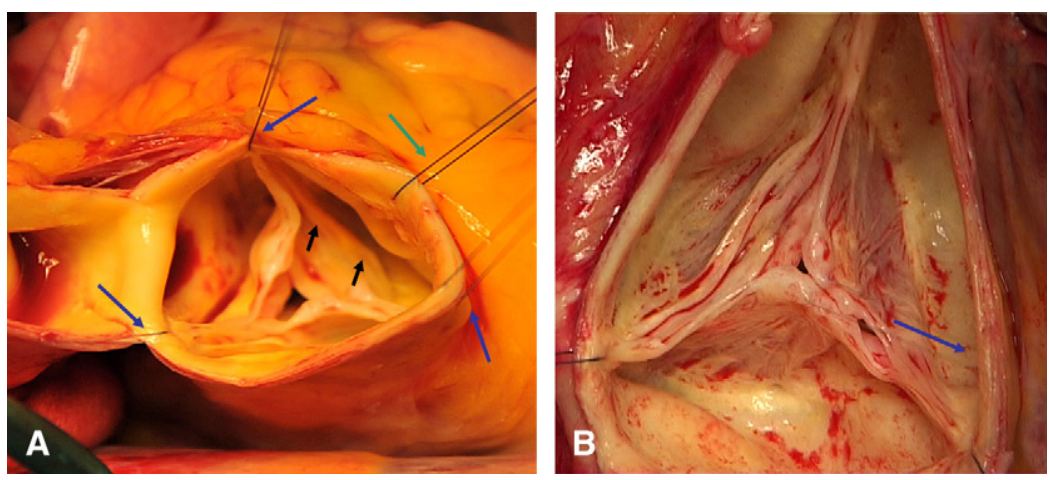

FIGURE 1. Aortotomy and valve assessment. A, After a transverse aortotomy $1 \mathrm{~cm}$ above the sinotubular junction, axial traction is applied (perpendicular to the annular plane) to the 3 commissural retraction sutures (blue arrows), and prolapse of the right coronary cusp and a fibrous band (black arrows) are observed. An additional retraction suture might facilitate exposure (green arrow). B, A 7-0 polypropylene suture is passed through the middle of the 2 reference cusps, and gentle upward traction (blue arrow) is applied. This indicates the desired height and free margin length of the prolapsing cusp.

cusp. In the rare case when all 3 cusps are prolapsing, the goal is to plicate the free margins enough so that the cusps coapt at the midpoint of the aortic sinuses.

In addition to cusp repair, the aortic annulus should be stabilized either by using subcommissural annuloplasty sutures (Figure 2,E) or root replacement with the reimplantation technique, if indicated. This maneuver will also help to increase the coaptation surface of the cusps.

We have used free margin plication in 55 consecutive patients either alone $(\mathrm{n}=34)$ or with free margin resuspension $(\mathrm{n}=21)$ for the correction of cusp prolapse in a trileaflet aortic valve. In this cohort, freedom from reoperation at 5 years
A
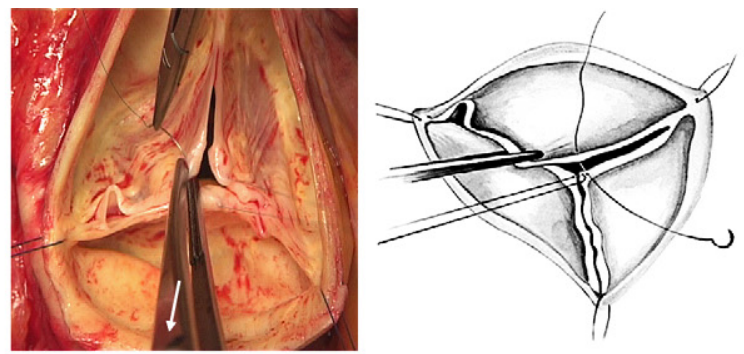

C
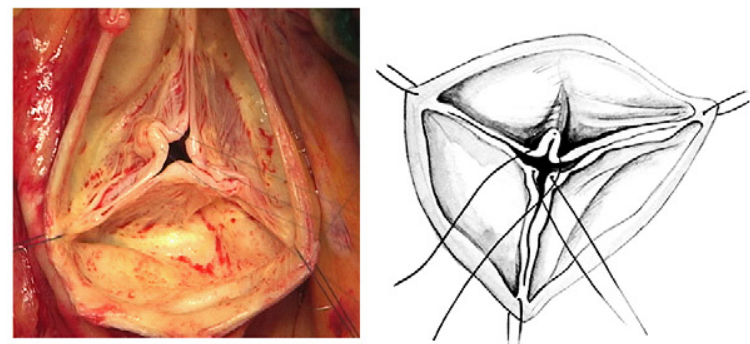

B
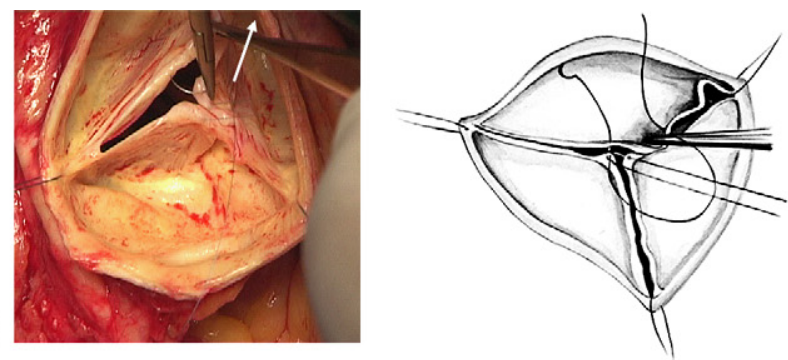

D
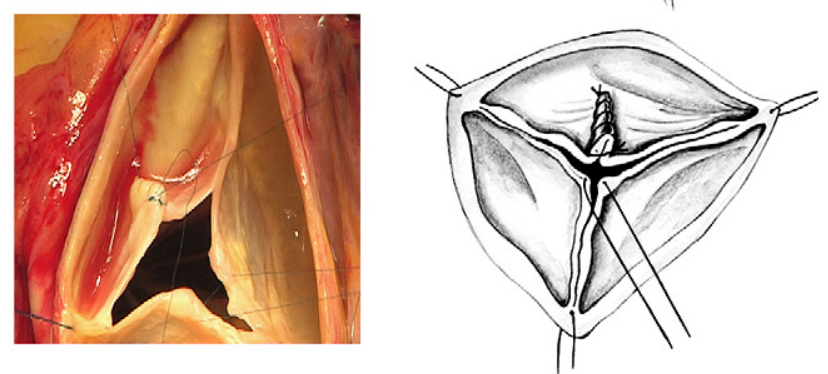

E

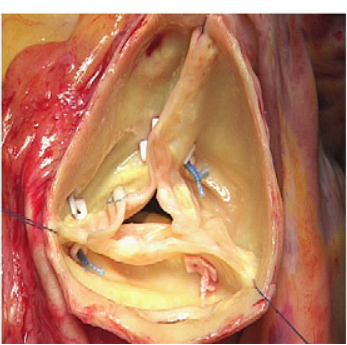

FIGURE 2. Quantification and correction of cusp prolapse. A, The prolapsing cusp is retracted parallel to the reference cusp (white arrow), and a 6-0 polypropylene suture is passed through the free margin from the aortic to ventricular side at the point at which it meets the center of the reference cusp. B, The direction of traction on the prolapsing cusp is reversed (white arrow), and the same suture is passed from the ventricular to the aortic side of the cusp, where it meets the middle of the reference cusp and the suture is tied $(\mathrm{C})$. D, The plication is extended by about 5 to $10 \mathrm{~mm}$ onto the body of the aortic cusp by adding interrupted or running locked 6-0 polypropylene sutures. E, Valve appearance after the addition of subcommissural annuloplasty sutures. 
and recurrent aortic insufficiency $(>2+)$ at 3 years was $100 \%$ in the plication-only group and $94 \% \pm 6 \%$ and $89 \% \pm$ $11 \%$ in the plication with resuspension group.

\section{DISCUSSION}

Free margin plication is an effective technique for the correction of cusp prolapse and can be performed in a simple and systematic manner with stable midterm results. It is ideally used in the presence of good-quality cusp tissue and can be used in conjunction with free margin resuspension.

\section{References}

1. Boodhwani M, de Kerchove L, Glineur D, Poncelet A, Rubay J, Astarci P, et al Repair-oriented classification of aortic insufficiency: Impact on surgical techniques and clinical outcomes. J Thorac Cardiovasc Surg. 2009;137:286-94.

2. Aicher D, Langer F, Adam O, Tscholl D, Lausberg H, Schafers HJ. Cusp repair in aortic valve reconstruction: does the technique affect stability? $J$ Thorac Cardiovasc Surg. 2007; 134:1533-9.

3. David TE, Armstrong S, Ivanov J, Webb GD. Aortic valve sparing operations: an update. Ann Thorac Surg. 1999;67:1840-2, 1853-6.

4. El Khoury G, Vanoverschelde JL, Glineur D, Poncelet A, Verhelst R, Astarci P, et al. Repair of aortic valve prolapse: experience with 44 patients. Eur J Cardiothorac Surg. 2004;26:628-33.

5. Schafers HJ, Bierbach B, Aicher D. A new approach to the assessment of aortic cusp geometry. J Thorac Cardiovasc Surg. 2006;132:436-8.

\title{
The incorporated aortomitral homograft: A new surgical option for double valve endocarditis
}

\author{
Jose L. Navia, MD, FACC, Sharif Al-Ruzzeh, PhD, FRCS, Steven Gordon, MD, Thomas Fraser, MD, \\ Oscar Agüero, MD, and Leonardo Rodríguez, MD, Cleveland, Ohio
}

The repair or reconstruction of a disrupted aortomitral curtain or intervalvular fibrous body (IFB), as a result of extensive endocarditis with abscess formation or of reoperation, is a challenge to the cardiac surgeon. ${ }^{1}$ In this report, we describe a new surgical technique for repair or reconstruction of the IFB in the setting of double valve endocarditis involving the aortic valve (AV), the mitral valve (MV) and IFB.

\section{CLINICAL SUMMARY}

A 57-year-old man was admitted electively after two episodes of MV and AV viridans streptococcal endocarditis. The patient was treated with antibiotics, and eventually grade 3 to 4 aortic regurgitation and grade 3 to 4 mitral regurgitation developed, as did paroxysmal atrial fibrillation. A combined procedure of bipolar radiofrequency ablation for atrial fibrillation as well as a new technique of aortomitral homograft as a single unit were discussed with the patient, who agreed to proceed and signed the informed consent form. This new technique was approved by the Institutional Review Board and Innovation Practice Committee of the Cleveland Clinic Foundation.

From the Cleveland Clinic, Cleveland, Ohio.

Disclosures: J.L.N. serves as a consultant to Cryolife Inc, Kennesaw, Ga.

Received for publication May 1, 2009; accepted for publication May 17, 2009; available ahead of print July 13, 2009.

Address for reprints: Jose L. Navia MD, FACC, Cleveland Clinic, 9500 Euclid Ave, Cleveland, OH 44195.

J Thorac Cardiovasc Surg 2010;139:1077-81

$0022-5223 / \$ 36.00$

Copyright (c) 2010 by The American Association for Thoracic Surgery

doi:10.1016/j.jtcvs.2009.05.017

\section{HOMOGRAFT PREPARATION}

The aortomitral homograft was prepared by Cryolife Inc (Kennesaw, Ga). It was harvested as a single unit by opening the left atrium, preserving the dome at the level of the aortic root. The MV annulus, leaflets, and subvalvular apparatus were anatomically evaluated, and the valve, anterior, and posterior leaflet heights were measured. The distal ascending aorta was then transected, and the AV, coronary ostia, and the ascending aorta were anatomically evaluated and measured. Then the left ventricle was opened below the papillary muscle level, and the whole MV was excised or removed by incision of the valve circumferentially. The incision was placed near the fibrous annulus of the valve and around the posterior area of the annulus, preserving the aortomitral membrane, the ascending aorta, the dome of the left atrium at the reflection of the aortic root, and the MV annulus intact as a single unit (Figure 1).

\section{PREOPERATIVE ECHOCARDIOGRAPHY}

An echocardiographic examination performed about a month before the operation showed severe grade 3 to 4 aortic regurgitation, with vegetations on the right and noncoronary cusps floating into the left ventricle and the aorta. This was seen as a linear echodensity $(0.5 \times 0.3 \mathrm{~cm})$ on the ventricular side of the $\mathrm{AV}$, consistent with a vegetation (Figure 2). It also showed severe grade 3 to 4 mitral regurgitation, posteriorly directed flow, and severe eccentric multiple shunts, as well as some potential perforation of the anterior leaflet of the MV. The multiple eccentric jets indicated involvement of the IFB, most probably by abscess and vegetation formation. There was a bright calcific 